\title{
Resemantizar la Independencia y pensar la ciudadanía: El proyecto de renovación del Museo de la Independencia Casa del Florero ${ }^{1}$
}

\section{Resumen}

A partir de la estrecha relación que existe entre las conmemoraciones rituales y los museos como dos formas de configuración y transmisión de la memoria social, el presente artículo analiza una propuesta museográfica desarrollada con motivo del Bicentenario de Independencia en Colombia (2010): el proyecto de renovación integral del Museo de la Independencia Casa del Florero en Bogotá (MICF), uno de los museos de historia más importantes del país que experimentó una remodelación tanto arquitectónica como de sus narrativas históricas y museológicas. El objetivo del texto es rastrear algunos de los desplazamientos de sentido en el relato histórico del museo, que pasa de considerarse un templo de la patria a constituirse en un foro de reflexión sobre la historia, la independencia y la ciudadanía.

Palabras clave: Colombia, museo histórico, museografía, historia, memoria colectiva.

Referencia para citar este artículo: VARGAS ÁLVAREZ, Sebastián (2016). "Resemantizar la Independencia y pensar la ciudadanía: El proyecto de renovación del Museo de la Independencia Casa del Florero". En Anuario de Historia Regional y de las Fronteras. 21 (2). pp. 75-100.

Sebastián Vargas Álvarez: Doctor en Historia (en curso), Universidad Iberoamericana. Magíster e historiador en Estudios Culturales, Pontificia Universidad Javeriana. Profesor del Departamento de Historia, Universidad Iberoamericana. Correo electrónico: legionesdeclio@gmail.com.

\footnotetext{
${ }^{1}$ Este artículo es un avance de investigación de mi tesis doctoral, desarrollada en el departamento de historia de la Universidad Iberoamericana, con el apoyo de la beca para adelantar estudios de doctorado en el exterior de Colciencias (Convocatoria 529 de 2011).
} 


\title{
Resemantizing Independence and Reflecting on Citizenry: the Renovation Project of the Museo de la Independencia Casa del Florero
}

\begin{abstract}
From the close relationship between the ritual commemorations and museums as two forms of configuration and transmission of social memory, this article analyzes a museum proposal developed on the occasion of the Bicentennial of the Independence in Colombia (2010): The comprehensive renovation project of the Museo de la Independencia Casa del Florero in Bogota (Spanish acronym MICF), one of the most important museums of history of the country, which experienced a remodeling of both its architecture and its historical and museological narratives. The aim of the text is to track some of the shifts of sense in the historical narrative of the museum, which goes from being considered a "temple of the homeland" to become a forum for reflection on history, Independence and citizenry.
\end{abstract}

Keywords: Colombia, Historical Museum, Museology, History, Collective Memory.

\section{Ressemantizar a Independência e pensar a cidadania: $O$ projeto de renovação do Museo de la Independencia Casa del Florero}

\section{Resumo}

A partir da estreita relação que existe entre as comemorações rituais e os museus como duas formas de configuração e transmissão da memória social, o presente artigo analisa uma proposta museugráfica desenvolvida com motivo do Bicentenário da Independência da Colômbia (2010): o projeto de renovação integral do Museo de la Independencia Casa del Florero em Bogotá (MICF), um dos museus de história mais importantes do país, que experimentou uma remodelação tanto arquitetônica como de suas narrativas históricas e museulógicas. $O$ objetivo do texto é rastrear alguns dos deslocamentos de sentido no relato histórico do museu, que passa de ser considerado um "templo da pátria" a constituir um fórum de reflexão sobre a história, a Independência e a cidadania.

Palavras chave: Colombia, museu histórico, museugrafia, história, memória coletiva. 


\section{Introducción: conmemoración y museo}

De tiempo atrás los museos se han flexibilizado mucho y ya no son los templos que convocaban a las musas de la creación, ni espacios de sacralización del pasado: son palestras de discusión y escenarios de producción de experiencias sensoriales y educativas. Son recintos vivos que, para preservarse y conservar su función útil a la comunidad, deben estar atentos a las nuevas necesidades de sus públicos y a las nuevas tecnologías, cuestionarse formas que fueron vigentes en el pasado para relacionase con su audiencia y desprenderse del faraónico espíritu de pleitesía ciega al pasado

Agustín Arteaga

Las conmemoraciones son rituales performativos que permiten a la sociedad reactualizar su memoria, y a partir de allí, reproducir y reafianzar o por el contrario cuestionar y problematizar sus identidades ${ }^{2}$. Se trata de ocasiones en las cuales pueden observarse cambios o permanencias en las formas en que la sociedad se relaciona con la historia, en la medida en que implican miradas hacia el pasado y proyecciones a futuro desde el presente. Los órdenes sociales se legitiman o se impugnan a partir de usos y lecturas particulares del pasado, especialmente cuando en el presente desde donde se evocan los acontecimientos fundacionales se experimentan crisis sociales, políticas o económicas ${ }^{3}$.

Por ende, las características de las conmemoraciones pueden arrojar luz sobre las percepciones que diversos sectores sociales tienen de la historia, la cultura y la identidad nacional ${ }^{4}$. Como acertademente comenta Eduardo Restrepo, la historización de la conmemoración habla más del presente que del pasado conmemorado: "[...] al igual que la celebración de hace un siglo, los actos y la agenda responden más a las preocupaciones e historicidad de quienes celebran, que a aquello supuestamente celebrado"5. También William Beezley y David Lorey argumentan en este sentido: las festividades públicas "[...] demuestran las percepciones cambiantes de las relaciones sociales y de los procesos culturales por parte de la gente congregada en estas conmemoraciones patrióticas" ${ }^{6}$, por lo que "[...] el análisis histórico del discurso

\footnotetext{
${ }^{2}$ Connerton, Paul. How societies remember (New York: Cambridge University Press, 2007); Moya, Laura y Olvera, Margarita (coords.). Conmemoraciones. Ritualizaciones, lugares mnemónicos y representaciones sociales (México: UAM-Azcapotzalco, 2012).

${ }^{3}$ Escobar, Juan Camilo y Maya, Adolfo Léon. "Memorar, conmemorar y representar las independencias iberoamericanas", en Escobar, Juan Camilo; Mojica, Sarah de y Maya, Adolfo Léon (eds.), Conmemoraciones y crisis. Procesos independentistas en Iberoamérica y la Nueva Granada (Bogotá: Universidad JaverianaEAFIT, 2012), pp. 25-42.

${ }^{4}$ Gillis, John. Commemorations. The politics of national identity (Princeton: Princenton University Press, 1994); Jelin, Elizabeth (comp). Las conmemoraciones: las disputas en las fechas 'in-felices' (Madrid: Siglo XXI, 2002).

${ }^{5}$ Restrepo, Eduardo. “¿Quién imagina la independencia? a propósito de la celebración del bicentenario en Colombia”, en Nómadas, núm. 33, Bogotá, Universidad Central, 2010, p. 74.

${ }^{6}$ Beezley, William y Lorey, David. "Introducction. The functions of Patriotic Ceremonies in Mexico", en Beezley, William y Lorey, David (eds.), ;Viva México! ;Viva la Independencia! Celebrations of September 16 (Wilmington: Scholarly Resources, 2001).
} 
público que se manifiesta en símbolos, performances, música y discursos permite acceder a aspectos del cambio histórico inaccesibles de otras formas"7.

El museo, por su parte, es una institución moderna clave en la configuración y transmisión de la memoria social en la medida en que colecciona, clasifica, investiga, preserva y exhibe aquellos objetos y tradiciones que en un momento dado se reconocen como parte del patrimonio cultural de una sociedad ${ }^{8}$. Las características y las funciones del museo han ido transformándose a lo largo de los siglos, pero su fin último de guardia de la memoria y constructor de la identidad de la sociedad en que se inscribe ha permanecido vigente ${ }^{9}$. Por lo tanto, no es de sorprenderse que los museos y las exhibiciones museográficas guarden una estrecha relación con las coyunturas conmemorativas. Algunas investigaciones han mostrado cómo una de las principales formas de representación de la nación y de construcción de la identidad nacional en Latinoamérica durante el siglo XIX y la primera parte del XX, fue la exhibición de los productos materiales y simbólicos de la comunidad imaginada en el marco de conmemoraciones, exposiciones, ferias nacionales y mundiales ${ }^{10}$.

Al tener en cuenta esta articulación, es posible acercarnos al espacio museal como "[...] un lugar de resonancia sobre lo que se celebra de la vida nacional, y como dispositivo de información para estudiar -a distancia- esas celebraciones y a quienes las realizan" ${ }^{11}$. Los museos y sus propuestas expositivas pueden ser utilizados entonces como fuentes para comprender las formas en que, en las coyunturas conmemorativas, diversos actores sociales pelean por la representación de la nación y su historia.

Este artículo analiza una propuesta museográfica desarrollada con motivo del Bicentenario de Independencia en Colombia (2010): el proyecto de renovación

\footnotetext{
${ }^{7}$ Ibid

${ }^{8}$ El International Council of Museums (ICOM), entidad encargada de coordinar los museos y los espacios patrimoniales a nivel mundial, define al museo como aquella "[...] institución permanente, sin fines de lucro, al servicio de la sociedad y abierta al público, que adquiere, conserva, estudia, expone y difunde el patrimonio material e inmaterial de la humanidad con fines de estudio, educación y recreo". ICOM. Definición del museo, http://icom.museum/la-vision/definicion-del-museo/L/1/ (24 de noviembre del 2015).

9 No es lo mismo hablar de un gabinete con curiosidades renacentista, que taxonomiza las especies naturales y/o los pueblos coloniales, restringido a nobles y eruditos; que de un museo nacional diseñado para construir y legitimar la historia, el arte y la identidad de la comunidad imaginada y cuyos destinatarios debían ser todos los ciudadanos; ni de un museo comunitario o barrial preocupado por patrimonios más locales o específicos. No obstante, el objetivo trascendente del museo de servir como lugar de memoria que es compartido en todos estos casos. Para una tipología de museos desde una perspectiva histórica: Fonseca, Alejandra y Vargas, Sebastián. "Museo: ¿piedra o relámpago? Reflexiones en torno a la relación museopúblicos", en Cuadernos de Curaduría, núm. 13, Bogotá, Museo Nacional, 2012.

${ }^{10}$ Tenorio, Mauricio. Artilugio de la nación moderna. México en las exposiciones universales 1880-1930 (México: Fondo de Cultura Económica, 1998); Martínez, Fréderic. “¿Cómo representar a Colombia? De las exposiciones mundiales a la exposición del Centenario: 1851-1910”, en Sánchez, Gonzalo y Wills, María Emma (eds.), Museo, Memoria y Nación (Bogotá: Museo Nacional, 2000), pp. 315-333.

${ }^{11}$ Machuca, Jesús Antonio. "Los museos como lugares de memoria”, en Gaceta de Museos, núm. 53, México, INAH, 2012, p. 5.
} 
integral del Museo de la Independencia-Casa del Florero en Bogotá (MICF), uno de los museos de historia más importantes del país, que experimentó una remodelación tanto arquitectónica como de sus narrativas históricas y museológicas. El objetivo del texto es rastrear algunos de los desplazamientos de sentido en el relato histórico del museo, que pasa de considerarse un templo de la patria a constituirse en un foro de reflexión sobre la historia, la independencia y la ciudadanía ${ }^{12}$.

En Colombia se presentaron varias y diversas exhibiciones de carácter histórico durante el Bicentenario ${ }^{13}$, pero se decide analizar la renovación del MICF por varias razones: i) el proyecto se enmarca dentro de una tradición de centralización de la memoria social (el museo queda ubicado junto a la plaza de Bolívar, en el corazón de la capital colombiana); ii) fue una de las propuestas museográficas más ambiciosas y costosas que emprendió el gobierno de Colombia, no solo para el Bicentenario sino en las últimas décadas ${ }^{14}$; y iii) el análisis permite establecer la transición entre dos tendencias divergentes de la representación histórica y de la función del museo: de una exposición histórica tradicional que posicionaba al museo como templo de la nación, se dio paso a una exhibición centrada en los conceptos de independencia y ciudadanía que desmitificó la historia patria y secularizó el espacio sagrado del museo, proponiéndolo más bien como un foro de discusión.

Si bien el análisis se detiene en las representaciones históricas de la propuesta, es preciso aclarar que existe una diferencia entre la escritura de la historia (la historiografía) y su despliegue en el espacio museal, mediante otro tipo de narraciones o inscripciones de sentido -museografias-, con sus propias características y particularidades. A diferencia de un libro de historia, en el museo la representación del pasado aparece atravesada por la construcción de un espacio narrado del campo visual que desborda la linealidad y la limitación (dada por el formato escrito) que constriñe a la historiografía, pues “[...] el lugar del museo opera un modo diferente de comunicar la escritura de la historia no solo porque la institucionaliza, sino también porque la hace pasar ineludiblemente por las operaciones museográficas que otorgan vida renovada a lo ya acontecido. A diferencia de la historiografía, el museo histórico se convierte en discurso dispuesto/cosa expuesta"15. El elemento de tridimensionalidad de los objetos exhibidos otorga características particulares

\footnotetext{
${ }^{12}$ El primero en utilizar estas metáforas fue el museólogo canadiense Duncan Cameron, en su conferencia de 1971: The museum a Temple or the Forum. Un fragmento de este texto puede leerse en Bolaño, María. La memoria del mundo. Cien años de museología 1900-2000 (Gijón: Trea, 2002), p. 278.

${ }^{13}$ Entre otras propuestas interesantes, pueden mencionarse a Palabras que nos cambiaron: lenguaje y poder en la Independencia, que contó con la curaduría de Margarita Garrido y se exhibió en la Biblioteca Luis Ángel Arango, y la exposición Las historias de un grito. 200 años de ser colombianos, del Museo Nacional. Para una reseña crítica de esta última: Vargas, Sebastián. "200 años de construir colombianos", en Memoria y Sociedad, vol. XIV, núm. 29, Bogotá, Universidad Javeriana, 2010, pp. 147-150.

${ }^{14}$ La prensa colombiana destacó la inversión, tanto económica como en términos de tiempo, realizada por el Ministerio de Cultura para la renovación del MICF. "Florero de Llorente estará a la vista; este martes abrirá sus puertas el Museo de la Independencia”, El Tiempo, Bogotá, 18 de julio del 2010.

${ }^{15}$ Morales, Luis Gerardo. "Límites narrativos de los museos de historia”, en Alteridades, núm. 37, México, UAM-Iztapalapa, 2009, pp. 44-45.
} 
como la hipertextualidad, la experimentación del espacio y la interacción social, que resultan imposibles o limitadas en la historiografía ${ }^{16}$.

Por otro lado, debe tenerse en cuenta que los museos, así como otros lugares de memoria, tienen su propia historia: "no solamente representan el pasado. Acumulan sus propios pasados"17. De allí la importancia de historizarlos: de identificar y comprender el contexto en el cuál nacen y las variaciones, los desplazamientos y las mutaciones que van teniendo a lo largo del tiempo. Toda vez que los museos, particularmente los de historia, han ostentado tradicionalmente la función de arconte o guardián de la memoria, el análisis de los museos y exposiciones históricas "[...] nos permite conocer parte de la cultura histórica de una sociedad, además de cómo ha cambiado la manera de jerarquizar los temas, los personajes y tratar los acontecimientos; en resumen, entender cómo documentamos y hacemos inteligible el pasado en función de las necesidades del presente"18; de los múltiples presentes desde los cuáles se lee el pasado: presentes que se superponen y constituyen las capas sedimentadas de la historia del museo $^{19}$.

\section{El proyecto de renovación}

La construcción colonial de finales del siglo XVI ubicada en la esquina de la carrera séptima y la calle once, en el costado nororiental de la Plaza de Bolívar, en el centro de Bogotá, es una de las edificaciones más importantes de la historia colombiana, pues en este sitio tuvo lugar la famosa reyerta del florero de Llorente del 20 de julio de 1810, considerada como el origen de la nación independiente según la historia patria y la tradición ${ }^{20}$. Esta casa es emblemática para la memoria oficial en el sentido en que se constituye en el sitio donde tiene lugar el acontecimiento fundacional del Estadonación (En esta casa nació la República, reza una placa colocada allí), hecho que queda sentenciado por los relatos posteriores de la historiografía y sus reproducciones en otros dispositivos de memoria. No obstante, el crecimiento urbano producto de la modernización e industrialización acelerada durante la primera mitad del siglo XX, y los disturbios que sufrió la ciudad luego de la revuelta popular conocida como el Bogotazo (desencadenada por el asesinato del líder liberal y candidato a la presidencia

\footnotetext{
${ }^{16}$ Velázquez, Cintia. "Arqueología del memorial del 68. Cómo y por qué reconstruir la historia de los museos de historia”, en Gaceta de Museos, núm. 53, México, INAH, 2012, p. 20.

${ }^{17}$ Dickinson, Greg; Blair, Carole y Ott, Brian (eds.). Places of public memory. The rethoric of Museums and Memorials (Tuscaloosa: University of Alabama press, 2010), p. 30.

${ }^{18}$ Velázquez, Cintia, Op. cit., p. 20.

${ }^{19}$ Crane, Susan. "The conundrum of ephemerality: time, memory and museums", en MacDonald, Shanon (ed.), A companion to museum studies (Malden: Blackwell, 2006), pp. 98-109.

${ }^{20}$ La pelea entre el comerciante español José González Llorente, quien tenía su negocio en la citada casa, y algunos criollos patriotas de la capital, estimuló una revuelta popular que tuvo como desenlace la institución de la Suprema Junta de Santa Fe. No obstante, en esta se continuó jurando fidelidad al rey Fernando VII y se nombró como presidente al virrey Amar y Borbón, por lo que la idea según la cual se dio la independencia en esa fecha es, al menos, cuestionable. Atehortúa, Adolfo León. 1810. Ni revolución ni nación (Medellín: La Carreta, 2010). Para un acercamiento a este acontecimiento desde la historia social: Rueda, Rigoberto. "El 20 de julio de 1810. Un episodio de protesta urbana en Bogotá", en Memoria y Sociedad, vol. XI, núm. 23, 2007, Bogotá, Universidad Javeriana, pp. 117-135.
} 
Jorge Eliécer Gaitán, el 9 de abril de 1948) habían sumido la casa en el abandono y la semidestrucción. Solo hasta finales de los años cincuenta, en la transición del gobierno de Gustavo Rojas Pinilla al de Alberto Lleras Camargo, el gobierno nacional comenzó las gestiones para la restauración del inmueble y la adecuación del museo. La tarea será encomendada a la Academia Colombiana de Historia, y en particular a uno de sus miembros más distinguidos, el historiador Guillermo Hernández de $\mathrm{Alba}^{21}$.

El museo se inauguró el 20 de julio de 1960 con motivo de los 150 años de la Independencia de la patria, y tomó su nombre de esta efeméride: Museo del 20 de julio. "Las realizaciones del lado oficial se monumentalizaron en esa ocasión en el ladrillo, madera, cemento y piedra [...] la construcción de un aventurado relato está cincelado en una placa, sobre cómo en esa casa habría nacido la república, o surgido "la libertad patriótica colombiana"'22. Sus primeras colecciones estuvieron integradas por una copia del Acta de Independencia (la original se perdió en el incendio de las Galerías Arrubla de 1900) y una colección de Constituciones de Colombia; el Memorial de Agravios de Camilo Torres; retratos, uniformes y documentos del general Francisco de Paula Santander y retratos al óleo de quienes tomaron parte en la gesta de Independencia. Varias de estas piezas fueron cedidas por otros museos, y otras más fueron donadas por particulares, muchos de ellos descendientes de notabilidades y figuras públicas consideradas relevantes durante la época de la Independencia, deseosos de honrar la memoria de sus ancestros, que por extensión también debían considerarse los padres tutelares de la nación ${ }^{23}$.

Las salas de las que se componía el museo estaban dedicadas a los principales personajes de la Independencia y la República (salas de Torres, Caldas, Santander,

\footnotetext{
${ }^{21}$ Cabe recordar que este organismo experto y público fue el que tuteló la educación histórica en Colombia desde su fundación en 1902 hasta bien avanzado el siglo XX, lo cual incluía su gestión e injerencia en los textos escolares, monumentos, conmemoraciones, y también museos: “[...] como espacio institucional de regulación del pasado de la nación, la Academia no solo veló por la producción de los escritos históricos, sino que llevó a cabo una administración de las fiestas patrias, los homenajes y las conmemoraciones, así como de la organización de archivos y museos. Precisamente una de sus funciones principales fue asesorar al Museo Nacional: los miembros de la Academia fueron autorizados desde el momento mismo de la creación de esta para visitar el museo cada vez que lo dispusieran y además se les permitió arreglar y clasificar los objetos relativos a sus campos de estudio". Pérez, Amada Carolina. "La memoria convertida en exhibición: adecuaciones de la sección de historia patria en el Museo Nacional de Colombia, 18801912”, en Ortega, Francisco y Chicanganá, Yobenj (eds.), Del dicho al hecho. 200 años de independencia y ciudadanía en Colombia (Bogotá: Universidad Javeriana, 2011), pp. 115-116.

${ }^{22}$ Rincón, Carlos. "Conmemoraciones y crisis. Centenario, sesquicentenario, Bicentenario”, en Escobar, Juan Camilo; Mojica, Sarah de y Maya, Adolfo Léon (eds.), Conmemoraciones y crisis. Procesos independentistas en Iberoamérica y la Nueva Granada (Bogotá: Universidad Javeriana- EAFIT, 2012), p. 17.

${ }^{23}$ Los lineamientos del museo en sus inicios dependieron de las decisiones de un reducido grupo de personas e instituciones, generalmente políticos o letrados reconocidos como descendientes de importantes personajes históricos. Adicionalmente, sus colecciones se formaron, en gran medida, a partir de "[...] convocatorias que se hicieron a prestantes familias bogotanas que además demostraran líneas genealógicas directamente vinculadas a protagonistas del período de la Independencia". Castro, Daniel. "El Museo del 20 de julio de 1810: entre la memoria literal y la memoria ejemplar (1960-2000)", (tesis de Maestría), Universidad Nacional de Colombia, 2012, p. 262.
} 
Nariño, etc.), así como a sus instituciones (salas de la Prensa, de la Junta Suprema) y símbolos (salas del Florero, del Acta). La idea era presentar un libro objetivo de historia a partir de estos objetos y espacios, según lo reconocía el director del museo en 1985:

[...] nos proponíamos hacer un libro objetivo de la historia de la Independencia nacional en el que cada sala constituyese un capítulo o monografía especial; de aquí sus denominaciones que al cabo de veinticinco años de la fundación, se encuentran saturadas de historia, de reliquias y de recuerdos auténticos de la época gloriosa a que está consagrado el museo ${ }^{24}$.

Al tomar como punto de partida el posicionamiento en la temporalidad -el Sesquicentenario de Independencia, evocación del mito de origen- y en la espacialidad -la casa como escenario del acontecimiento-, el museo se planteó como una institución de carácter tradicional y ortodoxa, caracterizada por " [...] su casi exclusiva vocación conservacionista centrada en los objetos, base de su colección y con ello la apelación a la autenticidad y originalidad de las piezas" ${ }^{25}$. Así mismo, era frecuente que los directivos del museo compararan a los objetos de la colección con reliquias y al museo como un venerable santuario de la Patria $^{26}$. En suma, se trataba de una institución de carácter devocional, dedicada a la veneración, el respeto y el recogimiento: “[...] espacios fríos, distantes y anclados en un pasado sesgado e inamovible centrado casi exclusivamente en la materialidad de sus acervos o en una específica interpretación de la historia"27.

Museo-templo que representó el lugar de enunciación y de legitimación de una minoría cultural y política bogotana y su específica interpretación de la historia nacional, bajo las direcciones de Guillermo Hernández de Alba (1960-1988), Carmen Ortega Ricaurte (1989-1999) y Luis Jaime Ezquerro (1999-2002). Dichos directores lograron blindar el proyecto museográfico original frente a los avances de la investigación histórica en el país y de la ciencia museológica en el mundo, campos que tuvieron un auge durante la segunda mitad del siglo XX. El museo se mantuvo como un recinto confinado únicamente al dominio del pasado y permaneció impasible frente a la actualidad política y los acontecimientos traumáticos de la historia reciente, como la toma del Palacio de Justicia por parte de la guerrilla del M-19 y la consecuente retoma por parte del Ejército Nacional el 6 y 7 de noviembre de 1985, evento en el cual ocupó un papel central (fue utilizado como base de operaciones de las fuerzas militares y se presume que allí fueron llevados con vida algunos de los doce desaparecidos que salieron con vida del Palacio). A pesar de la importancia y gravedad del hecho, este "[...] no logró afectar el devenir de la institución creada en 1960 en la que se había instaurado un mensaje de memoria literal y ejemplar sobre la Independencia, y

\footnotetext{
${ }^{24}$ Guillermo Hernández de Alba, citado en Castro, Daniel, Op. cit., p. 185.

${ }^{25}$ Ibid., p. 6.

${ }^{26}$ Ibid.

${ }^{27}$ Ibid.
} 
cómo esa intención permaneció inalterada aún después de esos graves y luctuosos acontecimientos" 28 .

Este modelo estuvo vigente por cerca de cuatro décadas, hasta cuando el Ministerio de Cultura (quien pasó a administrar el museo desde su fundación en 1997), consideró que el proyecto museográfico original no respondía ni a los lineamientos de la museología actual ni a las necesidades del público contemporáneo, por lo que, en miras de lo que sería la conmemoración del Bicentenario de la Independencia en 2010, el museo entró en un "proceso de renovación integral que se fundamenta en las necesidades de los visitantes y ciudadanos del siglo XXI"29. El modelo antiguo también se alejaba del paradigma pluricultural y multiétnico de nación instituido por la Constitución Política de 1991, al reconocer como sujetos históricos y artífices de la Independencia únicamente a un puñado de hombres que hacían parte de la élite capitalina.

El objetivo primario de este proceso de renovación era el de lograr:

[...] que los ciudadanos comprendan que más allá de una reyerta, lo que se gestó en ese lugar fue una nueva manera de comprender las relaciones de autonomía, libertad e independencia entre los futuros estados, y donde la tolerancia, el diálogo y la participación pluralista entre individuos y naciones sean hechos actuales, dinámicos, en un constante ejercicio de ciudadanía cultural y de revisión histórica de la Independencia ${ }^{30}$.

El proceso que empezó en 2004, estuvo liderado por el nuevo director del museo Daniel Castro (quien actualmente dirige el Museo Nacional), quien contempló varias etapas. En un primer momento, se llevó a cabo la remodelación arquitectónica con la restauración del inmueble original y la demolición de los edificios adjuntos que habían sido construidos a partir de 1960, así como con la construcción de un nuevo edificio y la adecuación de espacios al aire libre. Luego, entre 2007 y 2008, se realizó una consulta pública que indagó con respecto a lo que los ciudadanos esperaban encontrar en el nuevo museo. Entre 2008 y 2009 se adelantaron una serie de mesas de discusión con la participación del equipo del museo y profesionales en arquitectura, historia y museología. Algunas de las conclusiones derivadas de estos debates fueron: "la casa antigua es un testimonio y el edificio nuevo es un manifiesto"; se debe "explorar el sentido de la simultaneidad"; "Un museo de la Independencia debería tener una visión radical con respecto a cómo se explican los conceptos de libertad, democracia, nación"; "La ambición de este museo más que explicar el hecho histórico de la Independencia

\footnotetext{
${ }^{28} \mathrm{Al}$ respecto, Castro refiere que “[...] los trágicos sucesos del mes de noviembre de 1985, a escasos meses de que el museo hubiera celebrado los 25 años de fundación [...] crearon una especie de vacío en el que desaparecieron registros, evidencias y testimonios de los hechos, lo cual no en vano se puede dejar de comparar metafóricamente con esa exhaustiva limpieza que se realizó en el Palacio y en la Casa el 8 de noviembre de 1985 en el que se borró la memoria de lo acontecido [...] la institución sustituyó cualquier tipo de memoria de los hechos por el olvido, así siguiera argumentando su capacidad de ser un lugar de recordación del pasado histórico". Ibid., pp. 252-253.

${ }^{29}$ Ministerio de Cultura. Un nuevo museo para la Independencia. Museo de la Independencia-Casa del Florero (Bogotá: Ministerio de Cultura, 2012), p. 1.

${ }^{30}$ Ibid.
} 
es que el público entienda esos conceptos aplicados a su ciudadanía" ${ }^{31}$. El proyecto de renovación fue revisado durante el 2009 por diversos evaluadores externos, como Cristina Lleras (curadora del Museo Nacional), los profesores de la Facultad de Ciencias Humanas y Sociales de la Universidad Externado, Antanas Mockus (ex alcalde de Bogotá), la empresa de iluminación y museología española Intervento, el equipo del Museo Colonial, los historiadores Georges Lomné y Bernardo Tovar, y el Grupo de Investigación en Ciudadanías de la Universidad Nacional. Así mismo, fue socializado en espacios nacionales y extranjeros tales como la Universidad de los Andes, la Asociación Colombiana para el Avance de la Ciencia, la Red Nacional de Museos, el Seminario Internacional de Museografía (Puerto Rico), el Congreso de Colombianistas (University of Virginia), y la reunión del Comité de Educación y Acción Cultural (CECA-ICOM) (Islandia).

Castro da cuenta de cómo este proyecto articuló las inquietudes, las sugerencias y las necesidades no solo de los expertos sino también del público en general, a la vez que buscó hacer evidente un desplazamiento conceptual en el espacio museal -de templo de la patria dedicado al conocimiento (y veneración) de la historia, a foro de debate ciudadano de reflexión sobre la historia- al cambiar de nombre al museo:

[...] la renovación se llevó a cabo a partir de un proceso pedagógico que involucró participativamente a los visitantes del museo, así como a grupos de expertos, académicos y profesionales en diversas disciplinas. La fecha del 20 de julio fue designada fiesta nacional de Colombia en 1873 y recuerda los sucesos de revuelta popular que se llevaron a cabo en Bogotá, la capital del Nuevo Reino de Granada como colonia del Imperio español. El museo cambió su nombre en el proceso de renovación y sustituyó la fecha por el concepto de Museo de la Independencia ${ }^{32}$.

De esta manera, el Museo del 20 de julio daba paso al Museo de la IndependenciaCasa del Florero; la comprensión de la historia como acontecimiento fundante e instituido, cedía su lugar a una noción de independencia como proceso, abierta al cuestionamiento constante. En el mismo artículo, Castro relata que el proceso de renovación estuvo orientado por múltiples interrogantes: ¿cómo involucrar a los visitantes de manera activa en lugar de simplemente preguntarles lo que desean?, ¿cómo cambiar las preconcepciones históricas sobre los hechos ocurridos hace 200 años? y ¿cómo transformar la perspectiva del público acerca del carácter del museo como templo de la patria? Dichas preguntas se inscriben dentro de la tendencia de la nueva museología, que pone el acento sobre la relación entre museo y comunidad, así como en las posibilidades de intervención y transformación social.

Para poner en marcha las modificaciones que habían sido debatidas y propuestas en las fases anteriores del proyecto, el equipo del museo planteó tres esquemas

\footnotetext{
${ }^{31}$ Ibid. pp. 6 y 10.

${ }^{32}$ Castro, Daniel. "El nuevo Museo de la Independencia de Colombia”, en Humboldt, núm. 156, 2011, Bogotá, Instituto Goethe.
} 
museológicos, que estructuran la narrativa del MICF tal como se conoce actualmente: i) Un esquema de ciclos conmemorativos; ii) Una estructura de recorrido libre con dos rutas; iii) Un esquema de nodos temáticos que abordan variantes de los conceptos de ciudadanía e independencia ${ }^{33}$.

i) En primer lugar, la inauguración del museo renovado se planeó para julio del 2010, en el marco de las conmemoraciones del Bicentenario de Independencia, pero se quiso ir más allá de la conmemoración de la revuelta popular del 20 de julio y la institución de la Junta Suprema de Santa Fe, para ampliar la propuesta conmemorativa-reflexiva del museo por espacio de una década. De esta manera, el plan museológico tuvo en cuenta una serie de ciclos conmemorativos (iniciados en 2010 y proyectados hasta 2021): Ciclo 1: Múltiples miradas (2010-2013); Ciclo 2: ¿Qué tan boba fue la patria? Centralismo y Federalismo (2013-2015); Ciclo 3: Reconquista y Pacificación (20152017); Ciclo 4: Campañas libertadoras: guerra, guerrillas y guerrilleros (2017-2019); Ciclo 5: ¿Victorias militares? ¿Victorias políticas? (2019-2021). Los acontecimientos y problemas históricos conmemorados (y que están por conmemorarse) en este esquema de ciclos son abordados en el museo a partir de exposiciones temporales, recorridos especializados, conferencias, actividades educativas, etc.

ii) Los conceptos de Independencia y Ciudadanía se erigen como los ejes conceptuales que rigen la representación histórica y la disposición museológica/museográfica del MICF. Al tener en cuenta esto, el museo ofrece a sus visitantes la posibilidad de elegir entre dos rutas o recorridos a realizar, los cuales profundizan en uno de estos dos conceptos y convergen en la sala del Florero de Llorente, desde donde se puede tomar la ruta que no se eligió al principio y retornar al punto de partida. Según este esquema, la tienda de Llorente, en el primer piso, es el espacio de selección de ruta y la sala del Florero el espacio de transición (entre las dos posibilidades) ${ }^{34}$.

Para Daniel Castro, quien alude a la metáfora de la cinta de Möbius (una superficie con una sola cara y un solo borde que tiene la propiedad matemática de ser un objeto no orientable), el objetivo que se persigue con este esquema es "[...] generar tensión en el visitante al obligarlo a hacer una elección de recorrido (la Independencia es,

\footnotetext{
${ }^{33}$ Museo de la Independencia Casa del Florero. Manual institucional 2015-2016 (Bogotá: S.E., 2015). Agradezco al equipo del MICF, en particular a Pablo Vargas, Norma Jiménez y Alejandra Fonseca el haber compartido este documento así como demás información relacionada con el museo.

${ }^{34}$ Según este esquema, el concepto de independencia es abordado de la siguiente manera: "[...] a partir de la contextualización de los hechos que tuvieron lugar en Santafé el 20 de julio de 1810 y en particular en la edificación que hoy ocupa el Museo de la Independencia-Casa del Florero, se propone la reflexión y la revisión abierta del concepto de independencia, en contraste con otros como libertad y autonomía. Igualmente, se tendrán que desarrollar algunos ejercicios de historia comparada con los visitantes cuyo propósito es compartir, construir y contrastar las experiencias particulares relacionándolas con aspectos de la historia pasada"; mientras que por el de ciudadanía se "[...] comprende la exposición de las variadas experiencias e interpretaciones de lo que ha sido y significado el concepto de ciudadanía, dentro del marco interpretativo del proyecto actual de país y en torno al objeto-símbolo de la Independencia. En ella se presentan y analizan tanto los antecedentes, las causas, los efectos e influencias del proceso de Independencia en relación con la ciudadanía y sus efectos prácticos en la sociedad colombiana contemporánea". Ibid., pp. 17,19 y 20 .
} 
después de todo, una elección que implica decisión)" "35, elección que le permite andar y desandar el camino y así tener el panorama completo de la narración del museo ${ }^{36}$.

iii) Finalmente, al acompañar la estructura de las dos rutas, se encuentra el esquema de nodos temáticos, que "[...] abordan variantes de los conceptos de Independencia y Ciudadanía, desde el punto de vista histórico y de revisión contemporánea, nodos que están sujetos a una tarea de profundización investigativa que se llevará a cabo paralelamente al desarrollo de un proyecto de ampliación de espacios del Museo en un mediano plazo" ${ }^{37}$. Para la ruta de Ciudadanía los nodos propuestos son: El cabildo abierto, Comunidades políticas y bien común, Igualdad y diferencias, Soberanías, Mecanismos para ejercer la ciudadanía, Ciudadanías vulneradas; y para la ruta de Independencia son: Contextos, Revoluciones, el 20 de julio, Conmemoraciones.

Estos esquemas museológicos se concretaron en el espacio museal gracias a una propuesta museográfica arriesgada e innovadora, desarrollada por el brasileño Marcello Dantas, que se hizo reconocido a nivel internacional tras diseñar en 2006 el Museo de la Lengua Portuguesa en São Paulo. Dantas se ha especializado en crear lo que él llama museos de la identidad a partir de museografías inmersivas e interactivas. Además de la renovación del MICF, ha participado en la creación del Museo del Caribe en Barranquilla; el Museo Cocuruto, en la cima del Cerro Pan de Azúcar, Río de Janeiro; el de las Minas y el Metal, en Belo Horizonte; y el de las Telecomunicaciones en Río y en Belo Horizonte ${ }^{38}$. Para Dantas, de lo que se trata es de museografiar lo intangible, apelando a la producción de experiencias inmersivas en los visitantes: “[...] parto de la idea de que el público llega a un museo donde desconoce todo. Recurro a equipos de expertos que aportan la historia y los contenidos, y creo un lenguaje que le permita a la gente vivir una experiencia de inmersión. Mi objetivo es descubrir dónde está el territorio emocional de las personas" ${ }^{39}$.

Para poder fabricar estas producciones de presencia que le permiten contar una identidad, Dantas recurrió a las nuevas tecnologías y lenguajes multimedia: videoproyecciones, diapositivas $3 \mathrm{~d}$, audiovisuales, etc. Si el museo es el templo de

\footnotetext{
${ }^{35}$ Castro, Daniel, Op. cit. Cabe apuntar que este esquema es bastante similar al propuesto en el Museo Histórico Nacional argentino, también renovado recientemente. Di Liscia, María Silvia; Bohoslavsky, Mauricio y González de Oleaga, Marisa. "Del centenario al bicentenario. Memorias (y desmemorias) del Museo Histórico Nacional”, en A Contracorriente, vol. VII, núm. 3, Raleigh, North Carolina State University, 2010, pp. 100-125. Además, es muy importante tener en cuenta que los museos “[...] prescriben senderos particulares de entrada, atravesada y salida. Mapas, flechas, muros, límites, aperturas, puertas, modos de vigilancia, todos codifican poder y posibilidad", por lo que ninguna propuesta o esquema museológico/museográfico es inocente o aséptico. En este caso la posibilidad de elección se limita a los conceptos eje a partir de los cuales el MICF despliega su relato y representación de la historia. Dickinson, Greg; Blair, Carole y Ott, Brian, Op. cit., p. 29.

${ }^{36}$ Ibid.

${ }^{37}$ Museo de la Independencia Casa del Florero, Op. cit., p. 15.

${ }^{38}$ Reinoso, Susana. "Marcello Dantas: 'Hay que crear nuevos museos para la sociedad de la revolución digital”, en Revista Ñ, Buenos Aires, 2010.

39 Ibid.
} 
las musas, en la actualidad "[...] hay que crear nuevos museos para una sociedad atravesada por la revolución digital, convertir la inmaterialidad de la cultura en nuevos lenguajes expresivos"40. El trabajo de este experto brasileño se encontraba en sintonía con el proyecto de renovación del MICF, que perseguía una modalidad de exhibición interactiva y dinámica. Por lo tanto, fue contratado para “" [...] desarrollar un montaje que usó videos, interacción tecnológica y espacios de experiencia sensorial, en conjunto con las colecciones de piezas históricas que son de gran variedad y antigüedad"41. En consecuencia, la propuesta museográfica para la renovación del MICF puede enmarcarse dentro de una tendencia reciente de los museos de historia en donde se privilegian las escenografías virtuales y la generación de espacios y/o atmósferas envolventes por sobre los objetos y las narrativas escritas y lineales ${ }^{42}$. Tal como lo registró la prensa local en su momento, en la propuesta de Dantas “[...] el viejo adagio de 'mirar y no tocar se llama respetar' pierde vigencia para dar paso a un visitante activo que, valiéndose de sus cinco sentidos reconstruye hechos históricos y, lo más importante, se pregunta cómo estos afectan a su presente y si han dejado algún legado en su vida cotidiana"43.

El nuevo museo se inauguró el 20 de julio de 2010, en plena celebración del Bicentenario de la Independencia, y fue reabierto al público a partir del 1 de agosto del mismo año. Además de la exhibición de la colección permanente, hasta la fecha se han realizado diversas exposiciones temporales que coinciden con el calendario de ciclos conmemorativos contemplados en los esquemas museológicos: Independencia de Cartagena (2011), Más que muebles: diseño en tiempos de independencias (2012),

\footnotetext{
${ }^{40}$ Reinoso, Susana, Op. cit. El concepto de producción de presencia es propuesto en el interesante libro de Gumbrecht, Hans Ulrich. Producción de presencia: lo que el significado no puede transmitir (México: Universidad Iberoamericana, 2005).

${ }^{41}$ Castro, Daniel, Op. cit.

${ }^{42}$ Varios autores han llamado la atención sobre esta tendencia. De manera general, Adolfo Vázquez ha señalado que "[...] en las sociedades informatizadas y globalizadas, el museo ha sido desplazado de su papel hegemónico como administrador del régimen de visibilidad de una cultura, de dispositivo de verdad, para dar paso a nuevas prácticas artísticas de producción simbólica de imágenes y relatos -asociadas con la digitalización y la virtualidad- estrategias de reconocimiento siempre provisionales propias de las identidades en fuga y del tránsito constante". "Estética de la virtualidad y deconstrucción del museo como proyecto ilustrado", en Nómadas, núm. 28, Bogotá, Universidad Central, 2008, p. 124. Santacana y Hernández, por su parte, mencionan cómo cada vez con mayor frecuencia los museos de historia incluyen museografías hipermedia y ambientes escenográficos experimentales que invitan al visitante a participar y comprender mejor conceptos y contextos abstractos, así como el uso del audiovisual envolvente, formato que "[...] recrea la imagen que se hace del pasado; pone forma a las hipótesis de la misma manera que lo había hecho la pintura [...] es una forma de presentación del patrimonio que tiene capacidad de emocionar, ya que puede situar al 'espectador' en el centro del drama histórico". Museos de historia. Entre la taxidermia y el nomadismo (Gijón: Trea, 2011), pp. 205, 260 y 256. Finalmente, Américo Castilla se refiere a los efectos de este cambio de paradigma y de formatos sobre las maneras de representar la nación en los museos latinoamericanos: "[...] resulta curioso comprobar que para expresar una abstracción identitaria como el concepto de nación, en el pasado fuese necesario acumular objetos materiales. Por el contrario, para interactuar con un público que reúne una diversidad cambiante de identidades, el museo del siglo XXI tiende a prescindir de la centralidad de esos objetos". El museo en escena. Política y cultura en América Latina (Buenos Aires: Paidós, 2010), pp. 34 y 35.

${ }^{43}$ Semana, Op. cit.
} 
¿Patria boba? Primeros años de una nueva república (2013), Los héroes de los héroes (2014), ¿País a la medida? Colombia en palabras, imágenes y objetos (2015), entre otras.

Un análisis de las salas y los espacios del MICF da cuenta de la manera en que se han venido concretado las transformaciones y los desplazamientos conceptuales planteados en la propuesta de renovación integral. En primer lugar, se debe tener en cuenta que el edificio en donde se ubica el museo cuenta con dos pisos: en el primero se encuentra la entrada, un patio central, un jardín trasero, la recepción, la tienda, las oficinas de investigación y comunicación educativa y las salas: La tienda de Llorente, Más que criollos y La historia de la casa, la casa en la historia. En el segundo piso, se encuentran las demás salas, incluida la de exposiciones temporales, y las oficinas de catalogación, conservación, museografía y dirección.

Antes de entrar a las primeras salas, lo primero con lo que el visitante se encuentra es un espacio donde unas cédulas tituladas "Un solo tema, múltiples interpretaciones", "Diversas interpretaciones, un nuevo espacio" y "Umbral" explican cómo era el guion original del museo, en qué consistió el proceso de renovación museológica y arquitectónica y cuáles han sido las diferentes funciones y usos de la casa a lo largo del tiempo. Luego, se encuentra la sala Más que criollos, que se puede considerar introductoria, en donde se representa a través de diferentes objetos, videos y obras de arte, la diversidad de actores sociales que conformaban la sociedad neogranadina de finales del siglo XVIII y principios del XIX, en particular en la capital, así como sus aportes a la formación del país. El título de la sala es sugerente, en la medida en que persiste en el imaginario de la mayoría de los colombianos la idea de que la Independencia fue obra de los criollos. Entre los objetos exhibidos se puede mencionar la pintura Mercado en la Plaza Mayor de Santafé de Bogotá, de José Santiago Castillo (1837), y un dispositivo interactivo que muestra y pone en cuestión la clasificación racial por castas vigente en la época en soportes visuales como los cuadros de $\operatorname{castas}^{44}$ (figura 1). Es interesante notar cómo este mismo dispositivo vuelve a aparecer más adelante, en la sala Legados de ciudadanía, pero en vez de mostrar los diferentes resultados de las mezclas raciales (lobo, zambo, mulato o saltapatrás), todos y cada uno de los personajes comparten la misma denominación: ciudadano.

El recorrido continúa en La tienda de Llorente, en el mismo lugar en donde estaba ubicado el local comercial originalmente. Este espacio reconstruye la tienda y su contexto: exhibe productos comerciales de la época, tanto originales como réplicas (objetos suntuosos: joyas, telas, libros, porcelanas, etc.) y una pantalla táctil permite la indagación sobre la naturaleza, los usos y valores de las diversas mercancías, tanto

\footnotetext{
${ }^{44}$ Sobre las taxonomías raciales y su relación con la producción de conocimiento científico y las técnicas de gubernamentalidad biopolíticas entre finales del siglo XVIII y comienzos del XIX: Castro Gómez, Santiago. La hybris del punto cero. Ciencia raza e ilustración en la Nueva Granada (1750-1816) (Bogotá: Universidad Javeriana, 2005).
} 
en la época como en el presente ${ }^{45}$. Debe advertirse que para el 2015 la pantalla se encontraba averiada y fue reemplazada por un dispositivo museográfico manual. Esta sala hace énfasis en la cercanía de la casa y de la tienda con respecto a la Plaza Mayor, y da pistas sobre el contexto de la reyerta premeditada entre los criollos bogotanos y González Llorente, que desencadenó la revuelta popular del 20 de julio.

Figura 1: Dispositivo interactivo de la sala Más que criollos.

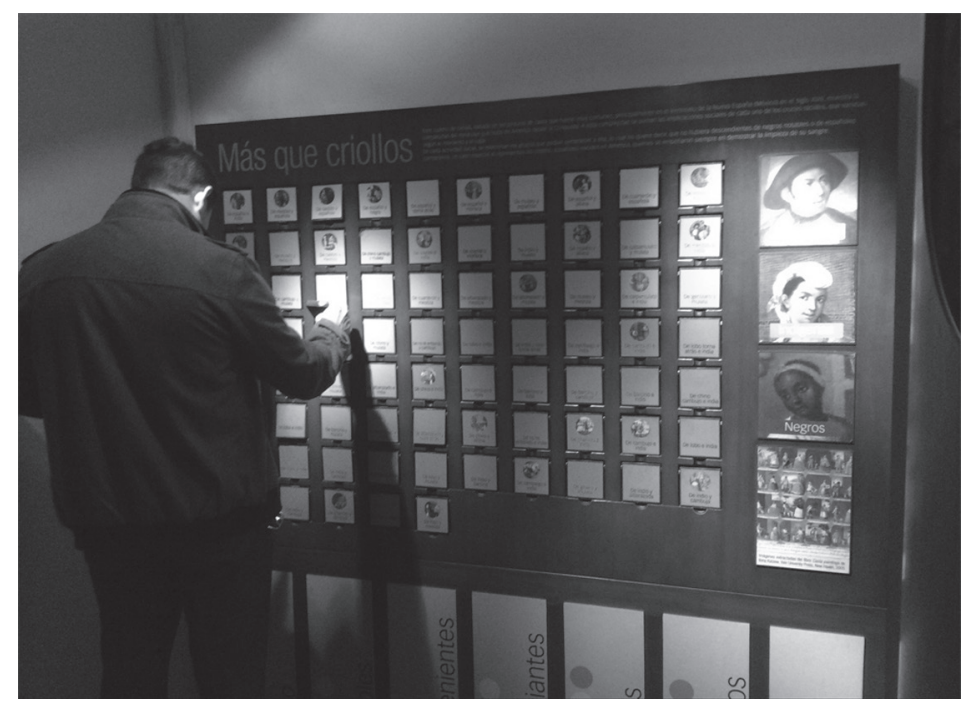

Fuente: Fotografía tomada por Alejandra Fonseca, 2015.

En La Historia de la casa, La casa en la historia se sitúa el papel desempeñado por la Casa del Florero en eventos relevantes en la historia del país como los cambios en la estructura de Bogotá hasta la actualidad, el Bogotazo del 9 de abril de 1948 y el Holocausto del Palacio de Justicia en 1985, a partir de objetos, documentos escritos, pinturas, fotografías e interactivos. En el centro de la sala al nivel del suelo se encontraba originalmente una proyección interactiva que representaba la Plaza de Bolívar (anteriormente Plaza Mayor) y que permitía al visitante modificar la manera en que se veía este lugar público dependiendo del año que se seleccionara con la mano (dicho recurso tampoco funciona actualmente y en su lugar se colocó un plano con algunas placas conmemorativas originales que marcan algunos momentos de la historia en la plaza). En esta sala también se rescatan los aportes de personajes claves en el proceso de Independencia invisibilizados por la historiografía tradicional, como el líder popular chispero José María Carbonell o el teólogo Ignacio Pescador, único firmante del Acta de Independencia de ascendencia indígena. Al final, se despliegan tres pantallas: una con animaciones a partir de retratos históricos de personajes como Antonio Nariño, Simón Bolívar y Policarpa Salavarrieta, los cuales remiten

\footnotetext{
${ }^{45}$ Por ejemplo, Juego de tazas y teteras procedentes de China: Valor en 1810, 48 reales, equivalente a un día de trabajo de un soldado de la época. Valor de hoy: 15.000 pesos, equivalente a dos horas de trabajo de un soldado de hoy.
} 
a la importancia de la Independencia; y otras dos con imágenes de archivo sobre el Bogotazo y la toma y retoma del Palacio de Justicia ${ }^{46}$.

A partir de este punto, se accede a la segunda planta por las escaleras, lugar de conexión en donde se presentan pequeños módulos explicativos o piezas en diálogo (de hecho, este tipo de piezas se encuentran diseminadas por todas las salas). Al momento de la etnografía se encontraba la pieza Acción de memoria, que repasa la intervención Sillas Vacías del Palacio de Justicia, que la artista Doris Salcedo realizó sobre la fachada oriental del palacio (la que se encuentra enfrente del museo) entre el 6 y el 7 de noviembre de 2002, y plantea el problema de los diferentes usos y apropiaciones de la plaza de Bolívar como lugar público central. El museo exhibe una de las sillas originales que utilizó Salcedo (Figura 2.).

Figura 2. Pieza en diálogo Acción de Memoria, realizada por Alejandra Fonseca y Daniel Castro.

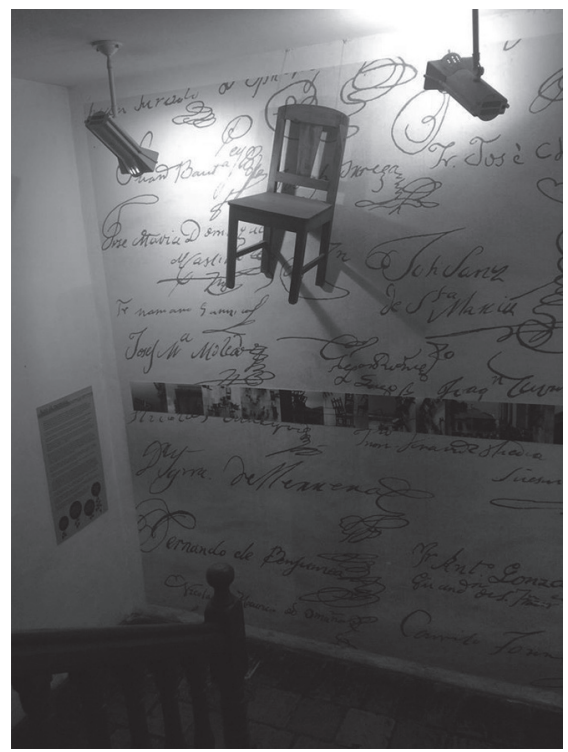

Fuente: Fotografía tomada por Alejandra Fonseca, 2015.

La sala Contextos de independencia presenta las diversas relaciones entre los acontecimientos revolucionarios acontecidos en Europa y en América entre finales del siglo XVIII y comienzos del siglo XIX, para evidenciar que la guerra de Independencia no fue un hecho aislado sino el resultado de tensiones que se presentaban en este periodo histórico en una escala global. Aquí se parte de una perspectiva transatlántica y compleja que desborda el marco interpretativo nacionalista para abordar el pasado,

\footnotetext{
${ }^{46}$ Sobre el tratamiento de este último acontecimiento en el MICF: Rincón, David. "Hecho Candente: La Toma del Palacio de Justicia: una aproximación a la representación museográfica del trauma histórico", (tesis maestría), ENCRYM-INAH, 2016.
} 
poniendo en diálogo la Revolución Francesa con la Revolución de los Comuneros, por ejemplo ${ }^{47}$. Así mismo, se da cuenta de la eclosión juntera en el contexto local y regional, al exhibir el Acta de Revolución (la bogotana, del 20 de julio) junto con otras, como el Acta de Constitución de la Provincia de Cartagena de 1811 (la primera en declarar total independencia con respecto de España). Todas estas relaciones se trazan a través de objetos (un retrato de Napoleón, un vaso de Carlos III, un busto de Policarpa Salavarrieta, una escultura de Santa Librada -patrona del 20 de julio-, espadas, monedas y emblemas, entre otros), una línea de tiempo titulada "Tiempos de revolución e independencias" y un gran telar que simboliza la manera en que los hilos de la historia están implicados con otras tramas.

En la sala del Florero se expone el objeto original que se supone dio pie a la reyerta del 20 de julio de 1810. Es pertinente aquí recordar que las piezas que constituyen las colecciones de los museos son objetos que han sido separados (detached) de su contexto y función originales para asumir una segunda vida como patrimonio ${ }^{48}$; son fragmentos de mundos de vida heterogéneos que se reúnen en el espacio museal con el objetivo de consolidar una memoria y un patrimonio (nacionales) por medio de su monumentalización y ritualización ${ }^{49}$. Así, el objeto fragmentado que deviene histórico al ser exhibido en el museo, "[...] adquiere un poder extraordinario [...] [que] reside en que es el soporte de una teoría, un relato, una ideología o un pensamiento filosófico o religioso" $" 50$. En este caso, el florero da soporte al relato histórico patrio según el cual el estallido de la Independencia fue obra de unos cuantos patricios criollos, que movilizaron a las capas populares de la capital y sus alrededores, el 20 de julio de 1810. El objeto-florero condensa el mito fundacional del estado-nación moderno colombiano.

Resulta entonces curioso -y en apariencia contradictorio-, que en la propuesta de renovación continúe siendo central este artefacto para la narrativa del museo, si se tiene en cuenta que las nuevas tendencias museológicas ponen el acento en los públicos más que en las colecciones (o más concretamente, en la interacción de los públicos con las colecciones $)^{51}$, y que el florero representa un mito patriótico que el nuevo guion pretende cuestionar.

\footnotetext{
${ }^{47}$ Dicha perspectiva se inscribe dentro de una tendencia historiográfica revisionista que debe mucho a los trabajos de François-Xavier Guerra en los años noventa y que estuvo en pleno auge durante los bicentenarios. Modernidad e Independencias. Ensayos sobre las revoluciones hispánicas (Madrid: Fondo de Cultura Económica-Mapfre, 1993); y Zermeño, Guillermo. "Sobre la condición postnacional en la historiografía contemporánea. El caso de Iberconceptos”, en Fernández Sebastián, Javier y Capellán de Miguel, Gonzalo (eds.), Conceptos politicos, tiempo e historia. Nuevos enfoques en historia conceptual (Santander: McGraw Hill-Universidad de Cantabria, 2013), pp. 463-489.

48 Kirshenblatt-Gimblett, Barbara. Destination culture. Tourism, museums and heritage (Berkeley: University of California Press, 1998), pp. 1-13.

${ }^{49}$ García Canclini, Néstor. "El porvenir del pasado", en Culturas híbridas. Estrategias para entrar y salir de la modernidad (México: Grijalbo, 1989), pp. 149 y 190.

${ }^{50}$ Santacana, Joan y Hernández, Francesc Xavier, Op. cit., p. 178.

${ }^{51}$ Alderoqui, Silvia y Pedersoli, Constanza. La educación en los museos. De los objetos a los visitantes (Buenos Aires: Paidós, 2011).
} 
Sin embargo, el florero es exhibido no con la intención de que sea venerado como un artefacto sagrado, como una reliquia nacional, sino como una pieza abierta a las interpretaciones y la interrogación: sobre el módulo y la vitrina en donde está ubicada la pieza, se colocaron globos de diálogo con fragmentos de testimonios sobre la reyerta (y el florero) provenientes de diferentes fuentes primarias y secundarias. Estos testimonios expresan una multiplicidad de miradas y versiones sobre el 20 de julio de 1810 que inhabilitan el cerramiento de este acontecimiento a un solo sentido: el canonizado por la historia patria.

Además, la exhibición del florero está acompañada por la proyección de un video en el que diferentes personas expresan lo que creen, conocen y sienten con respecto a esta pieza y a la historia que representa ${ }^{52}$. Se trata de hombres y mujeres de diferentes edades y profesiones (estudiantes, artistas, académicos), cuyos relatos sobre el florero son diversos y contradictorios, y hacen imposible una definición o una verdad absoluta sobre el objeto emblemático y la historia que representa. No obstante, a pesar de la pluralidad de voces que aparecen en el video, muchas de las cuales ponen en cuestión los mitos y los lugares comunes que se tejen alrededor del florero y del 20 de julio, la proyección está lejos de reflejar la diversidad cultural, étnica y regional del país, pues la mayoría de personas que allí participan pertenecen al segmento blanco-mestizo de la sociedad bogotana. Pese a esto, es importante mencionar que la museografía de la sala (la exhibición del florero con los globos de diálogo, así como la proyección del video) pretende hacer más verosímil y significativa la pieza, haciendo que los visitantes se interroguen por su sentido actual y no simplemente promoviéndolo como espectáculo o fetiche ${ }^{53}$. (Figura 3.).

La siguiente sala, Legados de ciudadanía, es una sala que originalmente constaba de una proyección en el techo (tipo planetario) y la instalación de varias hamacas en donde los visitantes podían recostarse para verla. El contenido del video plantea una reflexión sobre el legado más importante que han dejado las luchas por la independencia: la emergencia del ciudadano como sujeto político. La misma apuesta por las hamacas como espacio de descanso y reflexión es innovadora, pues rompe con las nociones y las prácticas tradicionales asociadas a un museo. Se trata de un espacio para todos los públicos, pero enfocado principalmente en los niños y los jóvenes. En la actualidad este sitio ha sido modificado por motivos técnicos, se ha transformado en una sala educativa que el 2015 presentó una exposición sobre Antonio Nariño, el precursor de la Independencia, y sus aportes con respecto a la construcción de ciudadanía en Colombia.

Estas últimas tres salas están conectadas por un corredor participativo, un espacio didáctico en donde se realizan acciones independientes, tales como intervenir el florero de Llorente con marcadores sobre un tablero, escribir actas de independencia personalizadas (“¿De qué quieres independizarte?”) o armar los rompecabezas

\footnotetext{
${ }^{52}$ El Florero de Llorente en el Museo de la Independencia-Casa del Florero, https://www.youtube.com/ watch? $=$ ZNS7BN2nXg0 (24 de noviembre del 2015).

${ }^{53}$ García Canclini, Néstor, Op. cit., p. 188.
} 
tridimensionales denominados Fragmentos de historia. Todas estas actividades ponen el acento en la articulación entre la historia (de la independencia) y la experiencia del visitante (su independencia), tal como se ha hecho en otros proyectos ${ }^{54}$.

Figura 3: Sala del Florero.

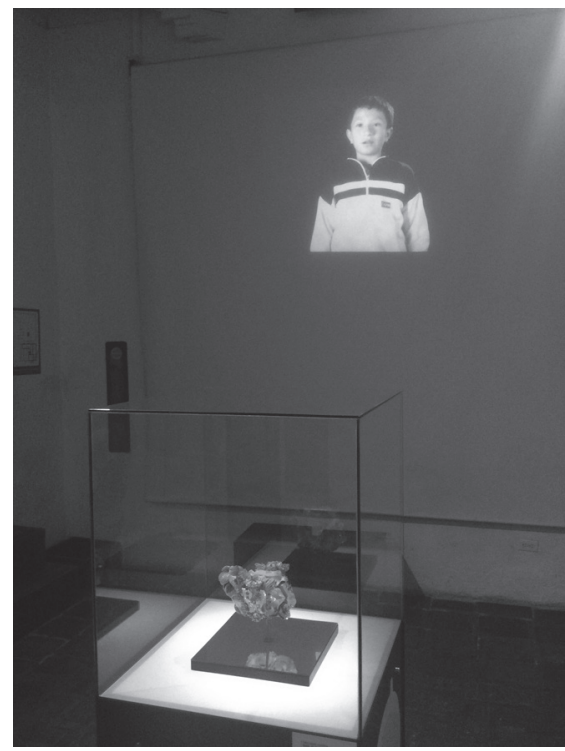

Fuente: Fotografía tomada por Alejandra Fonseca, 2015.

Finalmente, en la segunda planta también se encuentra la sala de exposiciones temporales. Para el segundo semestre de 2015 se encontraba en exhibición “¿País a la medida? Colombia en palabras imágenes y objetos", montada en conjunto con el Instituto Caro y Cuervo. Se trata de una muestra sobre las conexiones entre los procesos de construcción de la identidad nacional y las tecnologías, discursos y herramientas de conocimiento y medición del territorio y las poblaciones, desde la Expedición Botánica del siglo XVIII hasta los censos de los siglos XX y XXI ${ }^{55}$.

\section{Conclusiones: de templo a foro}

El análisis hasta aquí presentado permite arribar algunas conclusiones provisorias sobre el MICF. En primera instancia, se puede ver cómo el proyecto de renovación quiso aprovechar la conmemoración bicentenaria como una ocasión propicia para

\footnotetext{
${ }^{54}$ Vargas, Sebastián. "Taller Los jóvenes y el Bicentenario (Museo Colonial, 2010). Una experiencia alternativa de enseñanza/aprendizaje de la Historia", en Voces y Silencios: Revista Latinoamericana de Educación, núm. 4, Bogotá, Universidad de los Andes, 2013, pp. 18-44.

${ }^{55}$ Instituto Caro y Cuervo. "País a la medida. Colombia en palabras, imágenes y objetos", http://www. caroycuervo.gov.co/paisalamedida (24 de noviembre de 2015). Este tipo de exhibiciones guardan una estrecha relación con un reciente corpus de estudios que se han preguntado por las formas de representación de la nación, sus territorios y poblaciones desde el siglo XIX en adelante. Para un ejemplo reciente: Pérez, Amada Carolina. Nosotros y los otros. Las representaciones de la nación y sus habitantes 1880-1910 (Bogotá: Pontificia Universidad Javeriana, 2015).
} 
darle un giro al museo, en cuanto a la propuesta museológica/museográfica y a la narrativa histórica. Desmitificar el símbolo central que articulaba el relato del museotemplo anterior -el Florero-, equivale a desmitificar la historia patria; e incluir al visitante-ciudadano en la elaboración de los discursos del museo por medio de una propuesta interactiva, posibilita un ejercicio político de reflexión en torno a la Independencia y la ciudadanía en aras de una constante (re)construcción de la nación colombiana contemporánea.

Así mismo, en contraste con el modelo de 1960, la diferencia racial, regional y de género irrumpe en el museo, contribuyendo a resquebrajar la idea monolítica de nación que se había consagrado gracias a la historia patria transmitida en la escuela, las ceremonias y los museos durante la mayor parte del siglo XX. Se trata de un museo plural, acorde con el paradigma de nación multicultural propio de finales del siglo XX y comienzos del XXI (Figura 4.).

Figura 4: Patio principal del MICF. El planteamiento de la pregunta por la diversidad, en un museo abierto a la pluralidad.

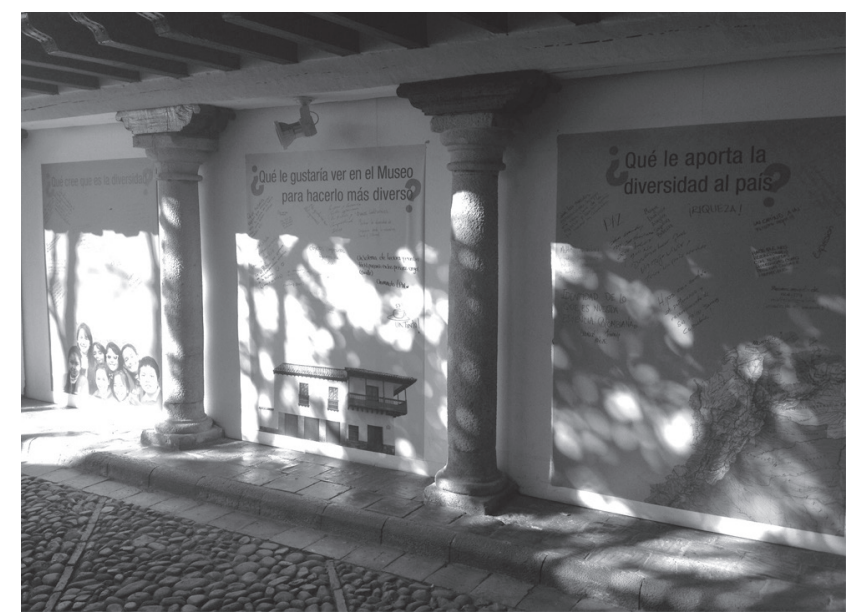

Fuente: Fotografía tomada por Alejandra Fonseca, 2015.

Por otro lado, si bien la Independencia (en tanto período histórico) mantiene su lugar privilegiado, esta se resemantiza y se pone en tensión con el concepto de ciudadanía: ya no se trata de un mítico e irrefutable tiempo de los orígenes, sino de una construcción histórica constante y de la cual se debe ser conscientes para poder contribuir a ella. La Independencia como algo inacabado y siempre en proceso: “¿Cuáles son las tareas pendientes de aquella época?", se pregunta Castro. Finalmente, el actual MICF hace más dinámicas las relaciones entre los tiempos históricos: no se aboca únicamente el pasado, sino que se ubica en el presente para cuestionar el pasado y proyectar el futuro; la inclusión del Holocausto del Palacio de Justicia en el guion es aquí fundamental. 
Ahora bien, ¿qué críticas o limitaciones pueden señalarse para este caso de estudio? En primer lugar, habría que señalar que la apuesta por la interactividad y por lo que el museógrafo Marcello Dantas llama lo espectacular ${ }^{56}$ conlleva algunos riesgos. Por ejemplo, puede generarse un desbalance entre los recursos multimedia utilizados y los propios contenidos históricos que estos pretenden transmitir: el público puede quedarse en el mero plano de la espectacularidad de las animaciones y los dispositivos interactivos, sin realmente ir más allá y desencadenar las reflexiones y cuestionamientos que el guion pretende estimular. Adicionalmente, estas propuestas museográficas focalizadas en la exposición mediante recursos multimedia que en piezas originales, suelen ser delicadas y dependen en buena medida del buen uso, funcionamiento y mantenimiento de equipos costosos de alta tecnología que se desgastan rápidamente y se dañan con facilidad. Se trata de museos altamente innovadores y llamativos para el público, pero que por contrapartida son bastante frágiles. Al igual que en otros museos de este tipo (como el Museo del Caribe) $)^{57}$, y a solo cinco años de su instalación, en el MICF ya se han deteriorado muchos de los dispositivos y aparatos interactivos, como pantallas táctiles, el plano digital de la plaza de Bolívar, el telar o la proyección en el techo, lo que ha obligado al equipo del museo a retirarlos, reemplazarlos e ingeniarse nuevos montajes museográficos que suplan su función narrativa-expositiva.

Por otra parte, no hay que perder de vista que este tipo de propuestas, que intentan representar actores y procesos históricos antes ignorados o marginalizados, pueden fácilmente deslizarse, -si no se es un visitante lo suficientemente crítico- y apuntar hacia miradas esteticistas, esencialistas, romantizadas o exotizantes de la diferencia. En este, y en todos los casos similares, sería pertinente mantener una ética de la sospecha y estar atentos para que este tipo de proyectos culturales nacionales que celebran la diversidad ${ }^{58}$ no se reduzcan a convertir el "[...] multiculturalismo en una técnica de gerencia, sustituyendo las políticas por exhibición, y enmascarando las desigualdades persistentes, el racismo, y el chauvinismo cultural detrás de los espectáculos de entretenimiento" 59 . En el ámbito museal, tanto los discursos plurales y políticamente correctos como la incorporación de nuevas tecnologías de la comunicación y la

\footnotetext{
${ }^{56}$ Lo espectacular tendría que ver con una manera aparentemente innovadora y entretenida de contar la historia a los públicos: “[...] el entretenimiento es una gran plataforma para el conocimiento. Un buen profesor puede contar buenos chistes sin dejar de ser un buen profesor. La vivencia de los hechos a través de la inmersión en ellos, la interactividad y la narrativa bien hecha son las mejores formas de contar una historia y provocar la reflexión. La historia es espectacular y debe ser contada de forma espectacular". Dantas citado en "El viejo florero en un nuevo lugar", Semana, http://www.semana.com/cultura/articulo/el-viejo-floreronuevo-lugar/117904-3 (24 de noviembre del 2015). Lo espectacular conlleva, no obstante, el riesgo de la banalización de lo expuesto y la reproducción de estereotipos y lugares comunes, particularmente cuando se representan las alteridades. Stuart Hall, "El espectáculo del otro".

${ }^{57}$ Para una aproximación crítica a este museo: Hernández, Bexielena. "Entre los límites de la representación y la construcción de ciudadanía: la nueva museografía en el Museo del Caribe", en Jaramillo, Gonzalo y Salge, Manuel (coords.), Los "teatros" de la memoria. Espacios y representaciones del patrimonio cultural en Colombia (Bogotá: Universidad de los Andes, 2012), pp. 61-74.

${ }^{58}$ Walkowitz, Daniel y Maya-Knauer Lisa (eds.). Contested histories in public space. Memory, race and nation (London \& Durham: Duke University Press), p. 5.

${ }^{59}$ Ibid.
} 
información pueden llegar a constituir un nuevo canon museográfico, ante el cual no se puede permanecer ingenuos ni acríticos.

Por otra parte, se encuentra cuestionable la supuesta posibilidad de elección de un recorrido: o bien por la ruta de la Independencia, o bien por la de la ciudadanía. En realidad todo visitante pasa en un primer momento por las tres primeras salas y es solo en la segunda planta en donde puede acceder a Contextos de la Independencia o Legados de ciudadanía antes de entrar a la sala del Florero. La pretensión de ofrecer al visitante un libre recorrido a su elección es una fórmula que queda reducida al plano retórico.

Con todo, es interesante comprobar que el caso de renovación integral de este museo da cuenta de cómo lo planteado a nivel histórico-museológico en un guion o plan siempre está sujeto a las contingencias cotidianas que atraviesan el museo a lo largo de su historia, y cómo desde lo museográfico se van ofreciendo soluciones concretas para hacer frente a los más disímiles retos. Lo cual equivale a recordar que, como planteé al comienzo del artículo, los museos poseen su propia historicidad.

En términos generales, se puede concluir que el proyecto de renovación del MICF se pensó como una propuesta museográfica acorde a la museología del siglo XXI, que contempla el museo más como un foro de discusión que como un templo de sacralización del pasado y el patrimonio, modelo propio de los siglos XIX y XX. A diferencia de los museos tradicionales de historia que "[...] se caracterizaron por proveer una información unidireccional y una voz institucional que no podía ser confrontada" ${ }^{60}$, esta propuesta, enmarcada en los prototipos de museo del nuevo milenio, quiso hacer converger en el museo múltiples voces e interpretaciones ${ }^{61}$. Jesús Antonio Machuca en un reciente artículo se hacía la siguiente pregunta sobre los museos y su representación de la nación y de la historia:

Una interrogante que queda en el aire es si los museos, que han sido una pieza fundamental en la tarea de definición de una conciencia histórica que incluye a la nación -al visualizar de manera crítica su propia manera de incidir en los modos de interpretar la historia-, podrán ahora incluir y mostrar la polifonía de las visiones, interpretaciones y memorias, así como hacer la historia de su propio papel y los modos de darla a conocer ${ }^{62}$.

El proyecto de renovación integral del MICF asume cabalmente esta tarea, al incluir y mostrar otras visiones, interpretaciones y memorias del pasado nacional, y al ser autoreflexivo en la medida en que tiene en cuenta y hace explícito el papel que a lo largo de la historia ha tenido el museo en la configuración de la memoria social y las identidades colectivas; puntualmente, el papel de la casa del florero en la historia del país. Estas conclusiones preliminares, no está de más decirlo, podrán ser corroboradas

\footnotetext{
${ }^{60}$ Castilla, Américo, Op. cit., p. 20.

${ }^{61}$ Ibid.

${ }^{62}$ Machuca, Jesús Antonio, Op. cit., p. 6.
} 
o cuestionadas por estudios de públicos que registren la recepción y apropiación de los discursos del museo por parte de los visitantes.

\section{Bibliografía}

\section{Fuente primaria}

\section{Proyectos}

Propuesta museográfica desarrollada con motivo del Bicentenario de Independencia en Colombia (2010). Proyecto de renovación integral del Museo de la IndependenciaCasa del Florero en Bogotá (MICF).

\section{Prensa}

El Tiempo, Bogotá, 2010.

\section{Fuentes secundarias}

\section{Libros}

Alderoqui, Silvia y Pedersoli, Constanza. La educación en los museos. De los objetos a los visitantes. Buenos Aires: Paidós, 2011.

Atehortúa, Adolfo León. 1810. Ni revolución ni nación, Medellín: La Carreta, 2010.

Bolaño, María. La memoria del mundo. Cien años de museología 1900-2000. Gijón: Trea, 2002.

Castilla, Américo (comp.). El museo en escena. Política y cultura en América Latina. Buenos Aires: Paidós, 2010.

Castro Gómez, Santiago. La hybris del punto cero. Ciencia raza e ilustración en la Nueva Granada (1750-1816). Bogotá: Universidad Javeriana, 2005.

Connerton, Paul. How societies remember. New York: Cambridge University Press, 2007.

Dickinson, Greg; Blair, Carole y Ott, Brian (eds.). Places of public memory. The rethoric of Museums and Memorials. Tuscaloosa: University of Alabama press, 2010.

Gillis, John. Commemorations. The politics of national identity. Princeton: Princenton University Press, 1994.

Guerra, François-Xavier. Modernidad e Independencias. Ensayos sobre las revoluciones hispánicas. Madrid: Fondo de Cultura Económica-Mapfre, 1993. 
Resemantizar la Independencia y pensar la ciudadanía: El proyecto de renovación...

Gumbrecht, Hans Ulrich. Producción de presencia: lo que el significado no puede transmitir. México: Universidad Iberoamericana, 2005.

Jelin, Elizabeth (comp.). Las conmemoraciones: las disputas en las fechas 'in-felices'. Madrid: Siglo XXI, 2002.

Kirshenblatt-Gimblett, Barbara. Destination culture. Tourism, museums and heritage. Berkeley: University of California Press, 1998.

Moya, Laura y Olvera, Margarita (coords.). Conmemoraciones. Ritualizaciones, lugares mnemónicos y representaciones sociales. México: UAM-Azcapotzalco, 2012.

Museo de la Independencia Casa del Florero. Manual institucional 2015-2016. Bogotá: S.E., 2015.

Pérez, Amada Carolina. Nosotros y los otros. Las representaciones de la nación y sus habitantes 1880-1910. Bogotá: Pontificia Universidad Javeriana, 2015.

Santacana, Joan y Hernández, Francesc Xavier. Museos de historia. Entre la taxidermia y el nomadismo. Gijon: Trea, 2011.

Tenorio, Mauricio. Artilugio de la nación moderna. México en las exposiciones universales 1880-1930. México: Fondo de Cultura Económica, 1998.

Walkowitz, Daniel y Maya-Knauer Lisa (eds.). Contested histories in public space. Memory, race and nation. London \& Durham: Duke University Press, 2009.

\section{Capítulos de libros}

Arteaga, Agustín. "El museo en perspectiva", en Territorio ideal, José María Velasco. Perspectivas de una época. México: MUNAL, 2014.

Beezley, William y Lorey, David. "Introducction. The functions of Patriotic Ceremonies in Mexico", en Beezley, William y Lorey, David (eds.), iViva México! ¡Viva la Independencia! Celebrations of September 16. Wilmington: Scholarly Resources, 2001.

Crane, Susan. "The conundrum of ephemerality: time, memory and museums", en MacDonald, Sharon (ed.), A companion to museum studies. Malden: Blackwell, 2006.

Escobar, Juan Camilo y Maya, Adolfo Léon. "Memorar, conmemorar y representar las independencias iberoamericanas", en Escobar, Juan Camilo; Mojica, Sarah de y Maya, Adolfo Léon (eds.), Conmemoraciones y crisis. Procesos independentistas en Iberoamérica y la Nueva Granada. Bogotá: Universidad Javeriana - EAFIT, 2012. 
García Canclini, Néstor. "El porvenir del pasado", en Culturas híbridas. Estrategias para entrar y salir de la modernidad. México: Grijalbo, 1989.

Hernández, Bexielena. "Entre los límites de la representación y la construcción de ciudadanía: la nueva museografía en el Museo del Caribe", en Jaramillo, Luis Gonzalo y Salge, Manuel (coords.), "Teatros" de la memoria. Espacios y representaciones del patrimonio cultural en Colombia. Bogotá: Universidad de los Andes, 2012.

Martínez, Fréderic. “¿Cómo representar a Colombia? De las exposiciones mundiales a la exposición del Centenario: 1851-1910", en Sánchez, Gonzalo y Wills, María Emma (eds.), Museo, Memoria y Nación. Bogotá: Museo Nacional, 2000.

Pérez, Amada Carolina. "La memoria convertida en exhibición: adecuaciones de la sección de historia patria en el Museo Nacional de Colombia, 1880-1912”, en Ortega, Francisco y Chicanganá, Yobenj (eds.), Del dicho al hecho. 200 años de independencia y ciudadanía en Colombia. Bogotá: Universidad Javeriana, 2011.

Rincón, Carlos. "Conmemoraciones y crisis. Centenario, sesquicentenario, Bicentenario", en Escobar, Juan Camilo; Mojica, Sarah de y Maya, Adolfo Léon (eds.), Conmemoraciones y crisis. Procesos independentistas en Iberoamérica y la Nueva Granada. Bogotá: Universidad Javeriana - EAFIT, 2012.

Zermeño, Guillermo. "Sobre la condición postnacional en la historiografía contemporánea. El caso de Iberconceptos”, en Fernández Sebastián, Javier y Capellán de Miguel, Gonzalo (eds.), Conceptos políticos, tiempo e historia. Nuevos enfoques en historia conceptual, Santander: McGraw Hill - Universidad de Cantabria, 2013.

\section{Artículos de revistas}

Castro, Daniel. "El nuevo Museo de la Independencia de Colombia", en Humboldt, núm. 156, 2011.

Di Liscia, María Silvia; Bohoslavsky, Mauricio y González de Oleaga, Marisa. "Del centenario al bicentenario. Memorias (y desmemorias) del Museo Histórico Nacional", en A Contracorriente, vol. VII, núm. 3, 2010.

Fonseca, Alejandra y Vargas, Sebastián. “Museo: ¿piedra o relámpago? Reflexiones en torno a la relación museo-públicos”, en Cuadernos de Curaduría, núm. 13, 2012.

Machuca, Jesús Antonio. "Los museos como lugares de memoria", en Gaceta de Museos, núm. 53, 2012.

Morales, Luis Gerardo. "Límites narrativos de los museos de historia”, en Alteridades, núm. 37, 2009.

Restrepo, Eduardo. “¿Quién imagina la independencia? a propósito de la celebración del bicentenario en Colombia”, en Nómadas, núm. 33, 2010. 
Rueda, Rigoberto. "El 20 de julio de 1810. Un episodio de protesta urbana en Bogotá", en Memoria y Sociedad, vol. XI, núm. 23, 2007.

Vargas, Sebastián. "Taller Los jóvenes y el Bicentenario (Museo Colonial, 2010). Una experiencia alternativa de enseñanza/aprendizaje de la Historia”, en Voces y Silencios: Revista Latinoamericana de Educación, núm. 4, 2013.

Vargas, Sebastián. "200 años de construir colombianos”, en Memoria y Sociedad, vol. XIV, núm. 29, 2010.

Vázquez, Adolfo. "Estética de la virtualidad y deconstrucción del museo como proyecto ilustrado", en Nómadas, núm. 28, 2008.

Velázquez, Cintia. “Arqueología del memorial del 68. Cómo y por qué reconstruir la historia de los museos de historia”, en Gaceta de Museos, núm. 53, 2012.

\section{Publicaciones en Internet}

ICOM. Definición del museo, http://icom.museum/la-vision/definicion-delmuseo/L/1/.

Instituto Caro y Cuervo. País a la medida. Colombia en palabras, imágenes y objetos, http://www.caroycuervo.gov.co/paisalamedida.

Ministerio de Cultura. Un nuevo museo para la Independencia. Museo de la Independencia-Casa del Florero, http:/www.quintadebolivar.gov.co/ museoindependencia/proyectobicentenario/Documents/unnuevomuseo.pdf.

Reinoso, Susana. "Marcello Dantas: 'Hay que crear nuevos museos para la sociedad de la revolución digital"”, en Revista N, 2011, http://www.revistaenie.clarin.com/arte/ Marcello-Dantas-museos-revolucion-digital_0_607739371.html.

"El viejo florero en un nuevo lugar", Semana, http://www.semana.com/cultura/ articulo/el-viejo-florero-nuevo-lugar/117904-3.

(Sin autor). El Florero de Llorente en el Museo de la Independencia-Casa del Florero, https://www.youtube.com/watch?v=ZNS7BN2nXg0.

\section{Tesis}

Castro, Daniel. El Museo del 20 de julio de 1810: entre la memoria literal y la menoria ejemplar (1960-2000), (tesis de Maestría), Universidad Nacional de Colombia, 2012.

Rincón, David. Hecho Candente: La Toma del Palacio de Justicia ": una aproximación a la representación museográfica del trauma histórico, (tesis maestría), ENCRYMINAH, 2016. 